\title{
Improved Maximum Power Point Tracking Algorithm for Photovoltaic Systems
}

\author{
L. MacIsaac ${ }^{1}$ A. Knox ${ }^{2}$ \\ ${ }^{1}$ Department of Electronics and Electrical Engineering \\ University of Glasgow \\ Glasgow. G12 8LT \\ Phone: +44 141330 2000, ext. 0112, E-mail: 1.macisaac@elec.gla.ac.uk \\ ${ }^{2}$ Department of Electronics and Electrical Engineering \\ University of Glasgow \\ Glasgow. G12 8LT \\ Phone: +44 141330 4253, E-mail: a.knox@elec.gla.ac.uk
}

\begin{abstract}
Research was carried out into existing methods of maximum power point tracking (MPPT) for photovoltaic systems. This paper compares existing approaches to maximum power point tracking and presents a new learning-based technique which exceeds the performance of existing methods.
\end{abstract}

Simulation and experimental results are presented which indicate that the new algorithm offers benefits over other methods described.

\section{Keywords}

Renewable Energy, Photovoltaic, Maximum Power Point Tracking

\section{Introduction}

Solar cells have a non-linear current-voltage characteristic and therefore the output power of a cell does not remain constant as the voltage across the cell varies. A variety of MPPT algorithms have been proposed which aim to adjust the voltage across a photovoltaic array so that it is operating at its maximum power point at all times. Two commonly used approaches to MPPT are the perturbation and observation and the incremental conductance methods.

This paper explains the current-voltage characteristics of photovoltaic systems and the operation of the perturbation and observation and incremental conductance algorithms. A new learning-based algorithm is then presented, along with the results of simulations and experiments which compare its performance with that of these other algorithms.

\section{Photovoltaic Characteristics}

\section{A. Simplified Solar Cell Model}

Solar cells have a nonlinear $\mathrm{I} / \mathrm{V}$ characteristic which is dependent on the level of solar irradiation and the cell temperature. A solar cell can be accurately modelled by a current source in parallel with a diode, as illustrated in Fig. 1. [1] $R_{P}$ and $R_{S}$ are the shunt and series resistances representing the losses in the photovoltaic conversion process and connections to the cell respectively.

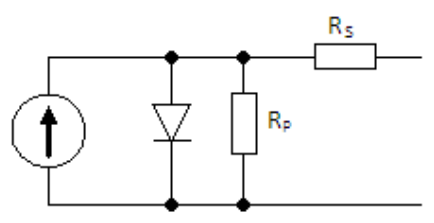

Fig. 1. Simple Solar Cell Model

Using the model of Fig. 1, the output current of a solar cell can be described in terms of the solar irradiation, cell temperature and voltage, as in (1).

$$
\begin{aligned}
I(S, T, V)= & I_{P H}(S)-I_{R S}(T)\left(\exp \left(\frac{V+R_{S} I}{m V_{T}}\right)-1\right) \\
& -\frac{V+R_{S} I}{R_{P}}
\end{aligned}
$$

Where $\mathrm{S}$ is the level of solar irradiation in $\mathrm{W} / \mathrm{m}^{2}, \mathrm{~T}$ is the solar cell temperature in Kelvin, $\mathrm{V}$ is the voltage across the cell in Volts and $\mathrm{m}$ is the dimensionless $\mathrm{P} / \mathrm{N}$ junction ideality factor of the diode in the model. $\mathrm{V}_{\mathrm{T}}(\mathrm{T})$ is the 
thermal voltage for a given temperature in Kelvin, given by $\mathrm{V}_{\mathrm{T}}(\mathrm{T})=\mathrm{kT} / \mathrm{q}$ where $\mathrm{k}$ is the Boltzmann constant $\left(1.39 \times 10^{-}\right.$ $\left.{ }^{23} \mathrm{~J} / \mathrm{K}\right)$ and $\mathrm{q}$ is the electron charge $\left(1.6 \times 10^{-19} \mathrm{C}\right) . \mathrm{R}_{\mathrm{S}}$ and $\mathrm{R}_{\mathrm{P}}$ are the series and shunt resistances in Ohms.

The photocurrent $\mathrm{I}_{\mathrm{PH}}$, generated by the photovoltaic conversion process, can be expressed in terms of the solar irradiation $S$, a reference level of solar irradiation $S_{R}$ and the photocurrent in Amps at the reference irradiation level $\mathrm{I}_{\mathrm{PHR}}$, as shown in (2).

$$
I_{P H}(S)=I_{P H R} \frac{S}{S_{R}}
$$

The reverse saturation current $I_{R S}$ is a loss in the conversion process due to a reverse current which flows through the diode, dependent on temperature. It can be expressed in terms of the cell temperature $\mathrm{T}(\mathrm{K})$, a reference temperature $T_{R}(K)$, the reverse saturation current at the reference temperature $I_{R S R}(A)$, the band gap energy of the semiconductor used to manufacture the cell $\varepsilon(1.12 \mathrm{eV}$ for silicon), the diode ideality factor, $\mathrm{m}$, and $\mathrm{V}_{\mathrm{T}}$ and $\mathrm{V}_{\mathrm{TR}}$ which are the thermal voltages at $T$ and $T_{R}$ respectively in volts.

$$
I_{R S}(T)=I_{R S R}\left(\frac{T}{T_{R}}\right)^{3} \exp \left(\frac{\varepsilon}{m}\left(\frac{1}{V_{T R}}-\frac{1}{V_{T}}\right)\right)
$$

To simplify the equation (1), it can be assumed that $R_{S}$ is sufficiently low and that $R_{P}$ is sufficiently high so that these resistances will have a negligible effect, giving (4).

$$
I(S, T, V)=I_{P H}(S)-I_{R S}(T)\left(\exp \left(\frac{V}{m V_{T}(T)}\right)-1\right)
$$

\section{B. Maximum Power Points}

The model from (4) was implemented in Matlab using the known reference parameters for an $80 \mathrm{~W}$ solar panel. The levels of solar irradiation and cell temperature were varied and the corresponding I/V curves were plotted, as shown in Fig. 2 and Fig. 3.

Fig. 2 and Fig. 3 show that the maximum power point is different for each combination of solar irradiation and temperature. A maximum power point tracking algorithm is therefore required to continuously adjust the solar cell's voltage so that it is operating at or close to its maximum power point at all times and under varying atmospheric conditions.

\section{Maximum Power Point Tracking Methods}

Two broad classes of MPPT algorithm are available. Model-based approaches use the model of the solar cell from (1) to accurately calculate and set the maximum power point. A model-based approach is presented in [1] which uses manufacturer-supplied data in addition to measurements of the solar irradiation and cell temperature.

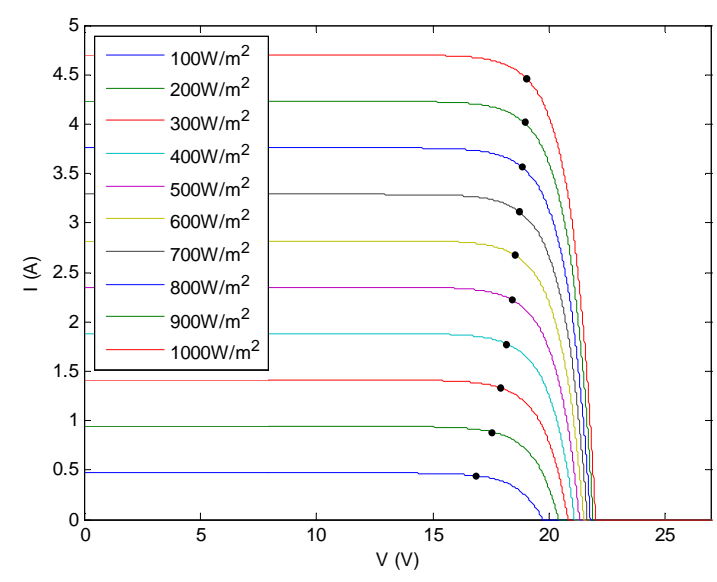

Fig. 2. Current-Voltage relationship of an $80 \mathrm{~W}$ solar cell under different solar irradiation levels. Temperature $=25^{\circ} \mathrm{C}$. The maximum power point is indicated on each curve.

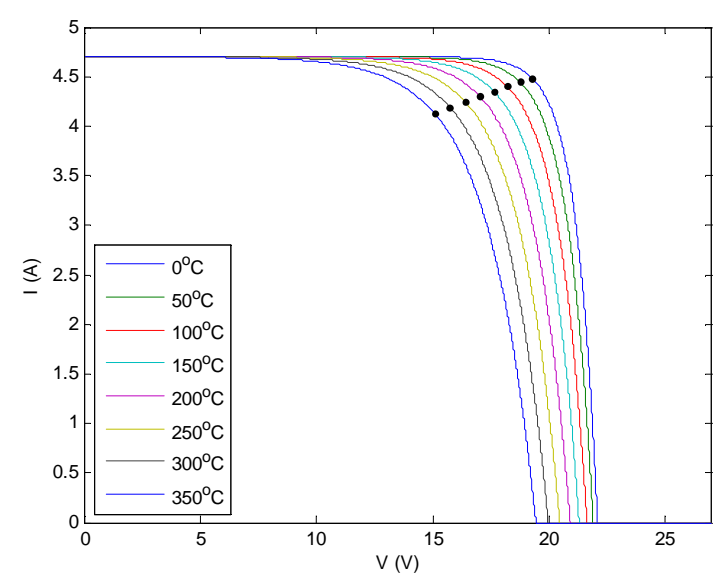

Fig. 3. Current-Voltage relationship of an $80 \mathrm{~W}$ solar cell under different cell temperatures. Solar Irradiation $=1000 \mathrm{~W} / \mathrm{m}^{2}$. The maximum power point is indicated on each curve.

Model-based approaches offer the benefit of being able to very accurately track the maximum power point regardless of how quickly atmospheric conditions change, but are closely coupled to the particular solar cell in use and require extra hardware to measure irradiation and temperature levels. Perturbation and observation based methods, described in the remainder of this section, provide a more generic approach to maximum power point tracking.

\section{A. Simple Perturbation and Observation}

The most basic form of perturbation and observation algorithm operates by making an adjustment to the operating voltage of a photovoltaic system and observing whether this yields and increase or decrease in the output power of the system. If an increase is observed, the algorithm continues to adjust the output voltage in the same direction. If a decrease is observed, the algorithm adjusts the voltage in the opposite direction. The overall effect of this algorithm, which is simple to implement, is that the 
output power of the system converges to close to the maximum power points, with some oscillation around the true maximum.

The hardware required to implement this type of algorithm consists of voltage and current transducers, a switched mode power supply and a device such as an FPGA or microcontroller to implement the control technique on. Several different types of optimisation of the algorithm such as varying the perturbation size [2] or varying the perturbation and sampling speed [3] are trivial to implement as they only require software changes in the control system.

\section{B. Incremental Conductance}

The Incremental Conductance algorithm [4] is an improvement on the basic perturbation and observation method that reduces the problems of oscillation around the maximum power point and tracking in the wrong direction during a change in atmospheric conditions. These improvements stem from the use of a technique which controls the perturbation direction based on the photovoltaic system's power-voltage curve.

The maximum power point represents a peak in the powervoltage curve of a solar cell, hence at this point $\mathrm{dP} / \mathrm{dV}=0$. At any point to the left of the maximum $\mathrm{dP} / \mathrm{dV}>0$ and to the right of the maximum $\mathrm{dP} / \mathrm{dV}<0$. Determining $\mathrm{dP} / \mathrm{dV}$ allows a decision on how to adjust the voltage to be made. The voltage should be increased if $\mathrm{dP} / \mathrm{dV}>0$ or decreased if $\mathrm{dP} / \mathrm{dV}<0$ to move closer to the maximum power point. If $\mathrm{dP} / \mathrm{dV}=0$ then no change should be made as the photovoltaic system is already operating at its maximum power point.

$\mathrm{dP} / \mathrm{dV}$ can be computed using (5) which requires only voltage and current measurements. [4] Voltage and current measurements can be taken directly from transducers while approximations for $\mathrm{dV}$ and $\mathrm{dI}$ can be made using (6) and (7) respectively. $V_{N}$ and $I_{N}$ are voltage and current readings taken during an iteration of the algorithm and $V_{B}$ and $I_{B}$ are the readings taken on the previous iteration of the algorithm.

$$
\begin{gathered}
\frac{d P}{d V}=\frac{d(I V)}{d V}=I+\frac{V d I}{d V} \\
d V=\left(V_{N}-V_{B}\right) \\
d I=\left(I_{N}-I_{B}\right)
\end{gathered}
$$

The addition of the curve-tracking technique ensures that the maximum power point is tracked correctly, even under rapidly changing atmospheric conditions. Additionally, by performing no voltage adjustments when the maximum power point is reached, losses caused by oscillating around the maximum are reduced. The hardware requirements of this algorithm are the same as those of the basic perturbation and observation algorithm which makes it an attractive replacement. Results from literature ([4], [5]) have shown that this algorithm provides significant improvements over simple perturbation and observation.

\section{Learning-Based Algorithm}

While Incremental Conductance addresses some of the shortcomings of basic Perturbation and Observation algorithms, a particular situation in which it continues to offer reduced efficiency is in its tracking stage when the operating point is moving between two significantly different maximum power points. For example, during cloud cover the maximum power point can change rapidly by a large value. Perturbation and Observation based techniques, including the Incremental Conductance algorithm, are limited in their tracking speed because they make fixed-size adjustments to the operating voltage on each iteration. The aim of the new algorithm is to improve the tracking speed of Perturbation and Observation based algorithms by storing current-voltage curves and their maximum power points and using a classifier based system.

\section{A. Finding the MPP}

To introduce this new algorithm, consider the I/V plot shown in Fig. 4. This plot provides a hypothetical example of different situations in which a perturbation and observation based technique was used to determine the maximum power point of the system. Fig. 4 illustrates sets of $\mathrm{I} / \mathrm{V}$ points which were recorded on each occasion that the algorithm tracked from one MPP to another and the MPP on each occasion. The benefit that the new algorithm aims to introduce is to quickly find the maximum power point for an unknown curve for which a single data value, $\mathrm{D}$, has been recorded.

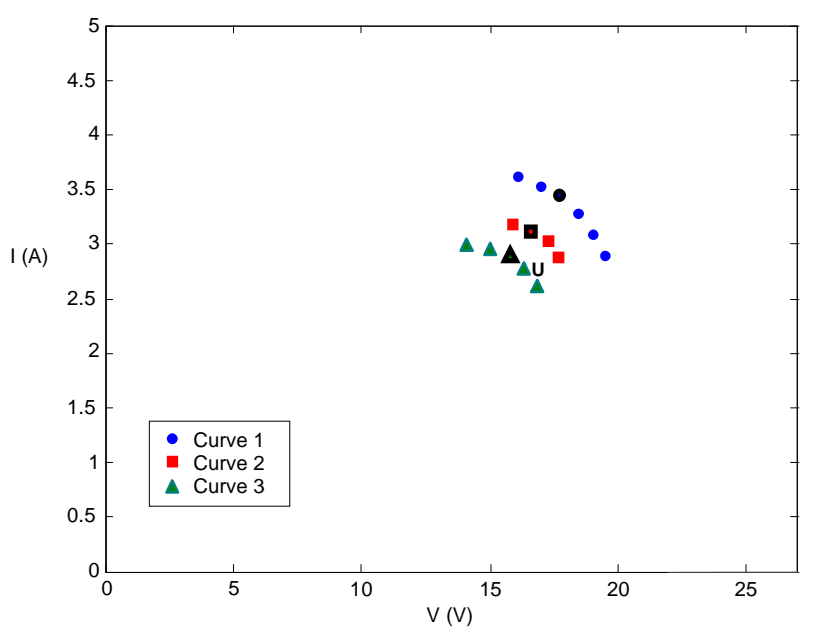

Fig. 4. Sample illustration showing points collected during different runs of a perturbation and observation algorithm and the maximum power point on each occasion (indicated in bold). 
To find the new maximum power point for the system, a $\mathrm{K}$ nearest neighbours classifier [6] can be used to find the nearest points to the recorded data point, U. In this case, taking $\mathrm{K}=3$, the nearest neighbours to $\mathrm{U}$ are two points belonging to curve 3 and a single point belonging to curve 2. At this stage it is assumed that $U$ lies on curve 3 and the operating voltage is set to the MPP for curve 3. A perturbation and observation technique is then used to refine the maximum power point until it begins to oscillate around the maximum. At this point the cell voltage is fixed and all of the $\mathrm{I} / \mathrm{V}$ points recorded during the perturbation and observation stage are stored.

\section{B. Storage of Curves}

Once the perturbation and observation stage is complete, the maximum power point is compared to the maximum power points of previously stored curves. If the maximum power point does not lie within a tolerance value $\pm \Delta \mathrm{P}$ of any other maximum power point, a new curve is defined and all of the recorded data points, the maximum power point $\left(\mathrm{P}_{\mathrm{MPP}}\right)$ and the maximum power point voltage $\left(\mathrm{V}_{\mathrm{MPP}}\right)$ are associated with that curve. If the maximum power point does lie within $\pm \Delta \mathrm{P}$ of an existing curve's maximum power point then the recorded data points are associated with the existing curve.

\section{Waiting State}

Once the new maximum power point has been found and the associated information recorded, the algorithm enters a waiting state where the power output of the solar cell is observed until it changes by more than a certain value $\mathrm{P}_{\text {DRIFT }}$. At this point, the classification and tracking process begins again.

\section{Formal Description}

A formal description of the algorithm is provided in Fig. 5.

\section{E. Expected Performance of Algorithm}

It is expected that the algorithm should initially perform similarly to the Perturbation and Observation algorithm but its performance should improve over time as it stores more data. Initial parameter choice will be an important factor in the performance of this algorithm. $\Delta \mathrm{P}$ affects the number of stored curves - larger values will result in less memory consumption but less accurate classification. However, too small a value of $\Delta \mathrm{P}$ will result in too much data being stored for classification to be effective. The value of $\mathrm{P}_{\mathrm{DRIFT}}$ determines how sensitive the algorithm is to changes in the MPP after it has been found. K determines how many data points should be used by the classifier. This value should be kept small to provide a locally sensitive classifier but large enough to disregard erroneous points.

\section{Comparison of Algorithms}

To compare the performance of the Perturbation and Observation, Incremental Conductance and Learning algorithms, a purpose-built simulation application was used which allows for comparison of the algorithms using a simulated solar cell model, as well as a comparison using a solar cell and electronic load.

\section{A. Simulations}

The simulator was set up to model the $80 \mathrm{~W}$ BP solar cell that would be used for the experimental part of the comparison. The instrumentation options in the simulator were set up to provide a current sensor with a minimum resolution of $78 \mathrm{~mA}$, a voltage sensor with a minimum resolution of $49 \mathrm{mV}$ and a minimum voltage adjustment of $100 \mathrm{mV}$. Additionally, the time taken to perform a voltage or current reading or adjust the voltage was set to $50 \mathrm{~ms}$. These parameters were selected to match the performance of the hardware used in the second part of the experiment.

Two standard test stimuli were devised to test the capabilities of each algorithm - the first providing slowly changing atmospheric conditions and the second providing rapidly changing conditions.

To compare the performance of the algorithms, the average power output of the simulated solar cell was recorded when performing each test. The results are summarised in Table I.

Table I. Results of tests using simulated solar cells.

\begin{tabular}{|l|l|l|l|}
\hline \multirow{2}{*}{} & \multicolumn{3}{|c|}{ Average Output Power (W) } \\
\cline { 2 - 4 } & $\begin{array}{c}\text { Perturbation } \\
\text { Observation }\end{array}$ & $\begin{array}{c}\text { Incremental } \\
\text { Conductance }\end{array}$ & $\begin{array}{c}\text { Learning } \\
\text { Algorithm }\end{array}$ \\
\hline $\begin{array}{l}\text { Slowly } \\
\text { Changing } \\
\text { Conditions }\end{array}$ & $50.0878 \mathrm{~W}$ & $50.0890 \mathrm{~W}$ & $50.4403 \mathrm{~W}$ \\
\hline $\begin{array}{l}\text { Rapidly } \\
\text { Changing } \\
\text { Conditions }\end{array}$ & $53.3551 \mathrm{~W}$ & $53.3736 \mathrm{~W}$ & $53.9427 \mathrm{~W}$ \\
\hline
\end{tabular}

\section{B. In-Circuit Experiments}

To compare the simulated results with an experimental situation, the simulator application was connected to a circuit containing two 80W BP solar panels and an Agilent electronic load - this circuit replaces the simulated solar cell used in the previous comparison. The electronic load provides the voltage and current readings from the solar panels and is used in constant voltage mode to adjust the panels' operating voltage as required by the MPPT algorithms. 


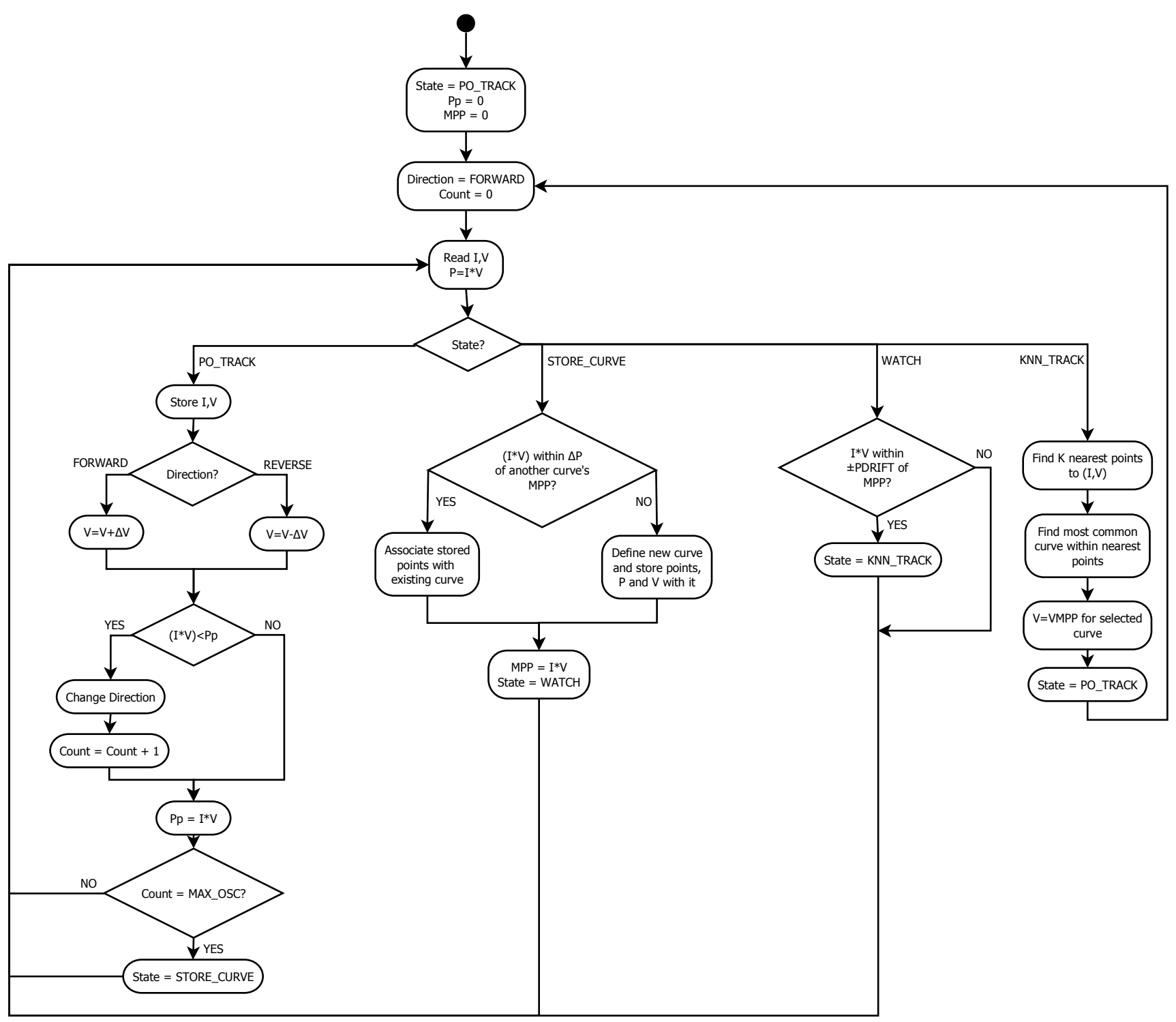

Fig. 5. Activity diagram illustrating learning-based maximum power point tracking algorithm.

As the experiment was carried out in a lab, control over atmospheric conditions was provided by using a $1 \mathrm{~kW}$ floodlight to illuminate the panels. The $1 \mathrm{~kW}$ floodlight was supplied through a VARIAC to allow its voltage and therefore the illumination level of the panels to be controlled. Again, two standard sets of test data were created to allow the three algorithms to be compared under both slowly changing atmospheric conditions and rapidly changing conditions. The results of the experimental comparison of the algorithms are given in Table II.

\section{Discussion of Results}

It can be observed from the simulation results that the new algorithm provides a higher average power output than the other two algorithms under both slowly and rapidly changing atmospheric conditions. However, the experimental comparison indicates that the Incremental
Conductance algorithm provides the better performance under slowly changing conditions, with the Learning Algorithm offering an improvement of $7 \%$ under rapidly changing conditions. The poorer performance of the new algorithm under experimental conditions can be attributed to the presence of noise in the experimental situation which was not modelled in the simulation. The noise causes the algorithm to oscillate at certain points during the tracking process which is the condition that the algorithm uses to detect that it has reached a maximum power point and stop tracking. The effect of this problem with the algorithm is less pronounced under rapidly changing conditions as the higher efficiency offered by the algorithm under these conditions mitigates the power lost due to the oscillation problem.

Fig. 6 illustrates the improvement in tracking that the Learning Algorithm offers over the existing perturbation- 
based methods studied. From Fig. 6(a) it can be observed that when the illumination level changes from 0 to $100 \%$, the Incremental Conductance algorithm takes some time to adjust the voltage from the previous maximum power point to the new maximum. However, in Fig. 6(b) it can be observed that the new algorithm provides improved performance by only having to carry out this tracking process once. On subsequent adjustments in the illumination level, it uses previously stored data to adjust the voltage to very close to the maximum power point before refining this estimate using perturbation and observation.

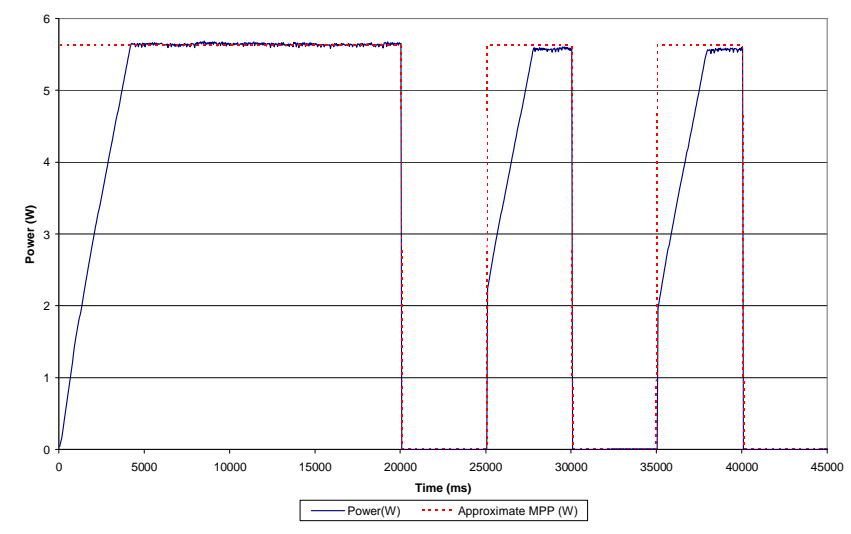

(a)
Table II. Results of experimental comparison of algorithms

\begin{tabular}{|l|l|l|l|}
\hline \multirow{2}{*}{} & \multicolumn{3}{|c|}{ Average Power Output } \\
\cline { 2 - 4 } & $\begin{array}{c}\text { Perturbation } \\
\text { Observation }\end{array}$ & $\begin{array}{c}\text { Incremental } \\
\text { Conductance }\end{array}$ & $\begin{array}{c}\text { Learning } \\
\text { Algorithm }\end{array}$ \\
\hline $\begin{array}{l}\text { Slowly } \\
\text { Changing } \\
\text { Conditions }\end{array}$ & $1.8206 \mathrm{~W}$ & $1.8214 \mathrm{~W}$ & $1.7875 \mathrm{~W}$ \\
\hline $\begin{array}{l}\text { Rapidly } \\
\text { Changing } \\
\text { Conditions }\end{array}$ & $2.4781 \mathrm{~W}$ & $2.5246 \mathrm{~W}$ & $2.7231 \mathrm{~W}$ \\
\hline
\end{tabular}

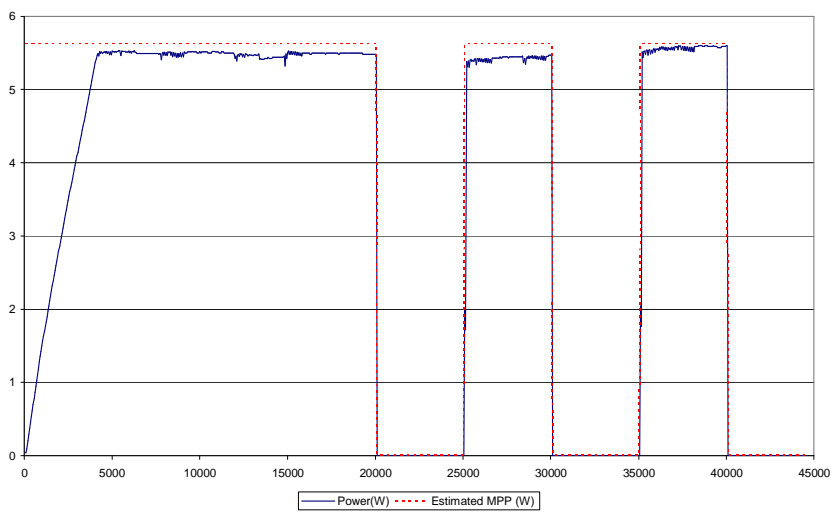

(b)

Fig. 6. Graphs comparing the performance of the (a) Incremental Conductance and (b) Learning Based maximum power point tracking algorithms. The estimated maximum power points were obtained from I/V curves of the solar panel under $0 \%$ and $100 \%$ illumination.

\section{Conclusion}

A new learning-based maximum power point tracking algorithm for photovoltaic systems has been presented which is based on a K-Nearest-Neighbours classifier. Simulation and experimental results have shown that this algorithm provides improved maximum power point tracking under rapidly changing atmospheric conditions, when compared to the Perturbation and Observation and Incremental Conductance Algorithms.

Further work is required to address some shortcomings of the algorithm. The original basis for the algorithm was the Perturbation and Observation technique which means that it may suffer from tracking in the wrong direction under rapidly changing conditions. Additionally, the algorithm detects that it has reached its maximum power point by detecting a set number of oscillations. A better approach would be to use the Incremental Conductance algorithm's slope detection technique to detect when the peak power point has been reached. Further work is also required into the methods used to select the best combination of parameters for the algorithm.

\section{References}

[1] M. A. Vitorino, L. V. Hartmann, A. M. N. Lima et al., "Using the model of the solar cell for determining the maximum power point of photovoltaic systems," Proc. European Conference on Power Electronics and Applications. pp. 1-10, 2007.

[2] J. Youngseok, S. Junghun, Y. Gwonjong et al., "Improved perturbation and observation method (IP\&O) of MPPT control for photovoltaic power systems," Conference Record of the Thirty-first IEEE Photovoltaic Specialists Conference. pp. 1788-1791, 2005.

[3] X. Liu, and L. A. C. Lopes, "An improved perturbation and observation maximum power point tracking algorithm for PV arrays," Proc. IEEE 35th Annual Power Electronics Specialists Conference. pp. 20052010 Vol.3, 2004.

[4] K. H. Hussein, I. Muta, T. Hoshino et al., "Maximum photovoltaic power tracking: an algorithm for rapidly changing atmospheric conditions," Generation, Transmission and Distribution, IEE Proceedings-, vol. 142, no. 1, pp. 59-64, 1995.

[5] G. M. S. Azevedo, M. C. Cavalcanti, K. C. Oliveira et al., "Evaluation of maximum power point tracking methods for grid connected photovoltaic systems," Proc. IEEE Power Electronics Specialists Conference. pp. 1456-1462, 2008.

[6] E. Alpaydin, Introduction to Machine Learning, Cambridge, MA: MIT Press, 2004. 